\title{
Intensive short-term dynamic psychotherapy to reduce rates of emergency department return visits for patients with medically unexplained symptoms: preliminary evidence from a pre-post intervention study
}

\author{
Allan Abbass, $\mathrm{MD}_{;}^{*}$ Samuel Campbell, $\mathrm{MB}, \mathrm{BCH}_{;}^{\dagger}$ Kirk Magee, MD, MSc; ${ }^{\dagger}$ Robert Tarzwell, $\mathrm{MD}^{\ddagger}$
}

\section{ABSTRACT}

Objective: Somatization of emotions accounts for excess emergency department (ED) visits in the form of medically unexplained symptoms (MUS). Intensive short-term dynamic psychotherapy (ISTDP) has been used to diagnose and manage somatization. We examined the effectiveness of this procedure for ED patients with MUS.

Methods: We implemented a service that included staff education, timely access to consultation and gathering of outcome data.

Results: Patients were assessed and treated shortly after referral. There was a mean reduction of 3.2 (69.0\%) ED visits per patient (standard deviation [SD] 6.4) the year afterward (95\% confidence interval $[\mathrm{Cl}] 1.3-5.0, p<0.001$ ). In comparison revisit rates during the same time interval for 3 available ED populations (i.e., those matched by visit rates, those with matching complaints and all patients referred to the service but never seen) showed either smaller reductions or higher ED use (ranging from a $15 \%$ reduction to a $43 \%$ increase). Treatments averaged 3.8 sessions per patient (SD 5.3). Selfreported symptoms improved significantly with the Brief Symptom Inventory global rating, which changed from a mean of 1.21 (SD 0.58) before assessment to 0.86 (SD 0.63) $(p<0.01)$ at the end of contact with the service. The service appeared acceptable to both emergency physicians and patients.

Conclusion: This emotion-focused assessment and treatment method appeared to be feasible and may be effective in reducing both symptoms and repeat ED use.

Keywords: somatization, medically unexplained symptoms, short-term dynamic psychotherapy
RÉSUMÉ

Objectif : La somatisation est responsable d'un nombre excessif de visites à l'urgence sous forme de consultation pour des symptômes physiques médicalement inexpliqués (SPMI). La psychothérapie dynamique brève a été employée pour diagnostiquer et prendre en charge la somatisation. Nous avons examiné son efficacité chez les patients présentant des SPMI.

Méthodes : Nous avons mis en place un service qui comprenait l'éducation du personnel, l'accès en temps opportun à une consultation et la collecte des données sur les résultats.

Résultats : Les patients étaient évalués et traités peu après la référence. On a noté une réduction moyenne de $69 \%(3,2$, écart-type $[E ́ T]=6,4)$ des visites à l'urgence par patient, dans I'année qui a suivi (intervalle de confiance [IC] à $95 \%$ de 1,3 à $5,0, p<0,001)$. Chez 3 autres groupes de patients à l'urgence (c'est-à-dire tous les patients à l'urgence, patients ayant des présentations semblables et tous les patients qui ont été dirigés au service, mais qui n'ont jamais été vus) avec qui on a comparé le nombre de visites subséquentes pour la même période, le taux de visite a connu une plus faible baisse ou a augmenté (une réduction de $15 \%$ à une augmentation de $43 \%)$. Les traitements ont duré en moyenne 3,8 séances par patient (ÉT $=5,3$ ). On a noté une amélioration significative des symptômes autodéclarés d'après l'échelle d'évaluation du bref inventaire des symptômes, le score ayant passé d'une moyenne de 1,21 (ÉT =0,58) avant l'évaluation à 0,86 (ÉT =0,63) $(p<0,01)$ à la fin de l'utilisation du service. Le service semblait acceptable pour les médecins d'urgence et les patients.

Conclusion : Cette méthode de diagnostic et de traitement axée sur les émotions semble être applicable et est susceptible de réduire les symptômes et les visites répétées à l'urgence.

From the Departments of *Psychiatry and †Emergency Medicine, Dalhousie University, Halifax, NS, and the ¥Department of Psychiatry, St. Paul's Hospital, and Faculty of Medicine, University of British Columbia, Vancouver, BC

Submitted Feb. 18, 2008; Revised Feb. 18, 2009; Accepted Mar. 24, 2009

This article has been peer reviewed. 


\section{INTRODUCTION}

Patients frequently present to the emergency department (ED) with medically unexplained symptoms (MUS). ${ }^{1}$ Anxiety and somatization may account for a significant portion of these cases, but emergency physicians (EPs) are sometimes reluctant to make these diagnoses. ${ }^{2,3}$ Fleet and colleagues ${ }^{4}$ reported that $25 \%$ of patients presenting to the ED with chest pain meet criteria for panic disorder based on the Diagnostic and Statistical Manual of Mental Disorders, 4th edition, ${ }^{5}$ yet the diagnosis is not made $98 \%$ of the time. Between 1998 and $2003,75.8 \%$ of 26430 patients presenting to our own ED with chest pain were given a discharge diagnosis of "chest pain not yet diagnosed" (chest pain NYD) as compared with only 3030 of 330000 all-cause ED presentations during the same interval, which were diagnosed as panic disorder (Queen Elizabeth II Health Sciences Centre emergency department database, Halifax, NS: unpublished data, 2005). Although EPs may be reluctant to "label" a patient with a psychiatric diagnosis, the episodic and brief nature of the typical ED encounter may also preclude establishing whether a condition is organic or psychological. ${ }^{1}$

Narrowly defined, somatization is the process by which emotions produce physical symptoms or anxiety about the body. In this context, somatization is caused by unconscious emotions and anxiety. Patterns of unconscious anxiety can be categorized in 4 main pathways: striated muscle tension, smooth muscle tension, cognitive perceptual disruption and conversion. ${ }^{6,7}$ Descriptions of these and common examples we have seen in the ED are in Table 1.

Short-term psychodynamic psychotherapy (STPP), a set of treatments targeting unconscious emotional processes, now has a moderate empirical base to support its use in somatization and symptom syndromes.
A current review of 23 studies of STPP for somatic symptoms found generally significant and sustained benefits. ${ }^{9}$ Two other studies found STPP to be superior to controls in treating panic disorder, ${ }^{10,11}$ which can be a frequent cause of MUS in the ED. ${ }^{12}$

One STPP method, intensive short-term dynamic psychotherapy (ISTDP), has demonstrated effectiveness in the treatment of panic disorder ${ }^{11}$ functional movement disorders, ${ }^{13}$ pelvic pain or urethral syndrome, ${ }^{14}$ chronic back pain ${ }^{15}$ and recurrent headaches. ${ }^{16}$ In one Canadian study ${ }^{17,18}$ treated patients experienced a marked drop in both physician visits and hospital use, which persisted at 1- and 3-year follow-up. Of relevance to the ED, ISTDP includes a method of "psychodiagnostic" evaluation that can allow one to detect emotional aspects of physical symptom, (i.e., presentations such as muscle tension-mediated chest pain). ${ }^{7,16}$ This study examines the impact of ISTDP-based diagnostic and treatment services for ED patients with MUS.

\section{METHODS}

\section{Study design}

This investigation used a pre-post design. We compared rates of ED visits in the year before the intervention with rates the year after the intervention.

\section{Setting}

The Queen Elizabeth II Health Sciences Centre, a university hospital in Halifax, was the site for this study. This urban ED sees an average of 60000 patients per year.

\section{Ethics}

The study was approved by the research ethics board of

Table 1. Somatization patterns and examples

\begin{tabular}{|c|c|c|}
\hline Somatization format & $\begin{array}{l}\text { Observations during emotion-focused } \\
\text { diagnostic assessment }\end{array}$ & Examples of ED presentations \\
\hline Striated muscle & $\begin{array}{l}\text { Progression from hand clenching, arm tension and } \\
\text { sighing respirations to whole-body tension }\end{array}$ & $\begin{array}{l}\text { Headache, globus, chest pain, hyperventilation, shortness } \\
\text { of breath, panic, backache, abdominal wall pain }\end{array}$ \\
\hline Smooth muscle & Acute or chronic spasm of smooth muscle & $\begin{array}{l}\text { Irritable bowel symptoms, abdominal cramps/pain, reflux, } \\
\text { nausea, bladder spasm, bronchospasm, coronary artery } \\
\text { spasm, hypertension, migraine }\end{array}$ \\
\hline $\begin{array}{l}\text { Cognitive perceptual } \\
\text { disruption }\end{array}$ & Anxiety affecting the cognitive and perceptual fields & $\begin{array}{l}\text { Visual blurring, blindness, mental confusion, dizziness, } \\
\text { pseudoseizures, paresthesias, fainting }\end{array}$ \\
\hline Conversion & Loss of tone in some or all voluntary muscles & Weakness, unilateral or bilateral paralysis, aphonia \\
\hline
\end{tabular}


the hospital and registered at ClinicalTrials.gov (ID NCT00833742).

\section{Participants}

All patients who were assessed by an EP from January 2002 to October 2006 and were given a provisional diagnosis of somatization, anxiety, or symptoms such as chest pain, abdominal pain or headache NYD were eligible for inclusion. All patients referred for an ISTDP assessment interview after urgent medical causes had been provisionally ruled out were included in the study. Patients with self-injury, suicidal ideation, psychosis and substance dependence were excluded. Patients were informed about the process and provided a pamphlet about the interview. They were then assessed a mean of 5.8 (SD 6.7, range 0.0-24.9) weeks later. After written informed consent, the interviews were videotaped for teaching and quality assurance purposes. Interviews were conducted in ED quiet rooms or in the hospital.

To acquaint EPs with the assessment and treatment methods, 2 video-based workshops and published articles were provided to the EPs. The workshops provided EPs with information about how to approach the patient and make referrals to the service. Moreover, for 1 month, a senior psychiatry resident was present in the ED full time to serve as a liaison. With the help of ED staff, a pamphlet describing the assessment procedure was developed and distributed in the ED to give to patients when making referrals. Referring EPs were provided a videotaped review of their cases to build awareness of and create a working relationship with this new service.

ISTDP began with a psychodiagnostic and evaluative interview that also served as a trial of therapy. ${ }^{6}$ The interview focused with the patient on life situations in which strong emotional activation occurred and examined the physical effects of that activation. Through this focus, both patient and physician could directly observe the patient's ability to identify and experience emotions. Any somatic effects of emotional dysregulation were also directly examinable by both. The presence of unconscious components of anxiety affecting the striated muscle, smooth muscle, motor tone or cognitive perceptual functioning were identified and managed by building awareness and by specific techniques to build anxiety tolerance. This single session consultation has been shown to significantly reduce Brief Symptom Inventory (BSI) ratings ${ }^{19}$ (i.e., somatic symptoms in a mixed patient sample). ${ }^{20}$

In some cases, follow-up treatment sessions tailored to the patient's anxiety tolerance and defensive patterns are recommended. The objective is to help the patient overcome defences and experience the feelings that led to the formation of symptoms and defences in the first place. In published studies ${ }^{21}$ treatment averaged 15-20 sessions, but 5 sessions can often help reduce symptoms. ${ }^{6}$ The treatment is not time-limited and decisions to terminate are made collectively by both the patient and the therapist. All sessions were videorecorded for self-review, supervision and adherence rating using a scale developed for research. ${ }^{22}$ The adherence rating scale has a cut-off score of 3 out of 4 where a score below 3 is considered nonadherent to treatment.

\section{Measures}

The primary outcome measure was the difference in the number of ED visits per patient before and after the emotion-focused assessment and treatment. Data for ED use were gathered retrospectively using hospital computer databases that covered all the regional EDs. The number of ED visits made by each participant for the periods 1 year before and 1 year after starting ISTDP treatment was counted by an administrative assistant.

The BSI, a validated self-report symptom measure, was used as a secondary outcome measure at the time of first assessment and at the end of contacts. This measure has normal cut-off values for each subscale and the total scale. For a 1-month period we collected written patient feedback on all new assessments. This form, which was developed for this service, included a Likert scale from 1 to 10 to rate overall satisfaction, and asked which components were helpful and what suggestions might improve the service. We did not seek formal feedback from EPs, but we examined rates of referral over the course of this study.

\section{Statistical analyses}

We compared rates of ED visits and BSI ratings before and after treatment using paired $t$ tests. We conducted sensitivity analyses to explore the influence of outliers across outcome measures.

\section{RESULTS}

\section{Sample}

The sample included mostly women (mean age $36.9 \mathrm{yr}$ ) with an average of $4.6 \mathrm{ED}$ visits in the previous year. 
Chest pain, abdominal pain, shortness of breath and headache were the top 4 complaints comprising twothirds of the referrals (Table 2).

\section{Clinical findings}

Of the 50 assessed patients, $40(80 \%)$ had probable somatization with symptom removal, symptom reduction or symptom reproduction during the assessment interviews. Four (8\%) had an unclear response, $2(4 \%)$ had mixed health problems with probable somatization and $1(2 \%)$ had a somatic delusion. Three $(6 \%)$ had responses suggesting that somatization did not account for the symptoms and that medical factors should be further explored. One of these was found to have pneumonia in short-term follow-up after a normal chest radiograph in the initial ED visit. Another was found to have pneumonia between the ED referral and consultation. A third was sent for a workup for epilepsy.

\section{Treatment}

With at least 2 years experience using this treatment model, evaluators included a psychologist (who saw 16 patients in this study, $n=16), 3$ senior psychiatry residents $(n=17)$, a psychiatrist $(n=10)$ and a family physician $(n=9)$. The number of treatment sessions averaged 3.8 (SD 5.3, range 1-25) including the initial assessment and any follow-up sessions. Twenty patients were seen only once for the initial assessment interview, 15 had 2 sessions and 15 had more than 2 sessions. Treatment adherence was found to average 3.4 (SD 0.8) on a 4-point scale. Seven cases were rated below the designated adherence cut-off of 3 .

\section{Emergency use}

There were $232 \mathrm{ED}$ visits among the 50 patients during a 1 -year period preintervention (mean 4.6 visits/patient, SD 8.3). Total ED visits decreased to 72 (mean 1.4 per patient, SD 2.7) in the postintervention phase, representing a $69 \%(3.2$, SD 6.4) ED visit per patient reduction $\left(95 \%\right.$ CI $\left.1.3-5.0, t_{49}=3.45, p<0.001\right)$. The number of treatment sessions correlated, nonsignificantly, with the difference in ED visits (Spearman $\rho=0.22$, $\rho=0.13$ ). Of 48 cases with adherence ratings, cases above the adherence cut-off had a 3.6 (SD 7.1) visit per patient reduction and those below the cut-off $(n=7)$ had only a 1.3 (SD 2.0) ED visit per patient reduction $\left(t_{46}=1.73, p=0.09\right)$.
To put observed revisit rates into some context, we examined the year over year revisit rates of 3 other patient groups. First, we examined revisit rates for all ED patients, which was weighted to match the ED visit distribution of the ISTDP treated group: we found mean visit rates went from 4.6 to 3.9 visits per patient, a $16 \%$ reduction. Second, we examined revisit rates for all ED patients with any of the same 4 main complaints (i.e., chest pain, abdominal pain, shortness of breath or headache), which were weighted to match the ED visit distribution of the ISTDP treated group. Here we found the mean visit rate went from a 4.6 to 4.4 visits per patient per year, a $4.3 \%$ reduction. Both these sets of data were derived from the years 2006 versus 2007 , as these data recently became available for such analyses.

Finally, we examined revisit rates for patients referred to the service but not seen. This sample included $27 \mathrm{pa}-$ tients who declined the offer $(n=9)$, did not need the service $(n=8)$, did not show up $(n=6)$ or did not return calls $(n=4)$. They had a similar pretreatment ED visit rate of 4.6 (SD 5.5) visits per year and there were no between-group statistical differences in age, sex or rates of chief complaints. This group had a $42 \%$ or 1.9 (SD 7.9 ) visit increase to 6.5 (SD 12.9) visits per year (95\% CI of difference -1.3 to $5.1, t_{26}=1.25, p=0.23$ ).

\section{Sensitivity analyses}

Because the data were skewed and mixed populations were present, we conducted sensitivity analyses. Excluding those $(n=2)$ with more than 20 treatment sessions, those with more than 10 ED visits before ISTDP treatment $(n=3)$, those with low adherence ratings $(n=7)$ or those found to have organic etiologies in their ED presentations $(n=7)$ did not materially affect the results.

\begin{tabular}{|c|c|c|}
\hline Characteristic & No. $1 \%$ & of patients ${ }^{*}$ \\
\hline Mean (SD) age, yr & 36.9 & (14.0) \\
\hline Female sex & 35 & $(70)$ \\
\hline Mean (SD) ED visits 1 year before & 4.6 & $(8.2)$ \\
\hline \multicolumn{3}{|l|}{ Main complaint } \\
\hline Chest pain & 14 & $(28)$ \\
\hline Abdominal pain & 8 & $(16)$ \\
\hline Shortness of breath & 7 & $(14)$ \\
\hline Headache & 4 & (8) \\
\hline
\end{tabular}




\section{Self-report symptom outcomes}

Twenty-six patients who had 2 or more sessions repeated the BSI after assessment and treatment sessions. This subgroup had a mean of 5.1 (SD 5.7) treatment sessions. They reported significant improvement going from 1.21 (SD 0.58) to 0.86 (SD 0.63, $t_{25}=2.84$, $p<0.01$ ) on the BSI global rating and 1.61 (SD 1.1) to 1.04 (SD 1.0, $t_{21}=2.45, p=0.02$ ) on the somatization subscale. These posttreatment means approached the BSI's pathological cut-off levels expected for this group of 0.82 and 0.94 , respectively. ${ }^{23}$

\section{Patient satisfaction}

Over a 1-month period, 13 patient satisfaction surveys were collected from the 14 patients assessed (1 patient declined to complete). They rated overall satisfaction at 7.4 out of 10 (SD 2.1, range 4-10) corresponding to the level between "satisfied" and "very satisfied" on this Likert scale. Patients were generally appreciative, expressed gaining insight into the physical effects of emotions and expressed benefit from the process.

\section{Staff physician referrals}

Referrals increased with 5 referrals from 3 EPs during the first year to 45 from 12 EPs in the final year of this evaluation. At the time of this writing, the ED and hospital have applied to the provincial ministry of health for funding to staff the ED full time with trained professionals to provide ISTDP-based diagnostic and treatment services.

\section{DISCUSSION}

This study has specific limitations to highlight. First, there was no randomized control group. Selection biases on the part of EPs may have led to the referral of patients more likely to respond to treatment. A large number of referred patients were never seen, even though they continued to visit the ED. We have no way of knowing if these patients would have benefited from this service. We did not measure the use of other health resources, including family physicians or mental health teams before and after referral. Previous research has found persistent reduction in all physician contact with this method. ${ }^{17} \mathrm{We}$ did not distinguish ED visits by cause, and many ED visits may have been for illness of defined organic etiology. Finally, we lack a complete data set of patient-reported outcomes because of incomplete follow-up.

Although we cannot definitively state that it was this service that led to the benefits observed, several lines of evidence suggest that the treatment may have been the key factor. First, positive findings were seen across reductions in ED use, patient symptom ratings, referral rates and patient satisfaction ratings. Second, treated patients had greater reduction of ED use than available comparison groups. The finding of no visit reduction in the "referred but never seen" sample suggests that simply being assessed and referred to the service was not sufficient to reduce ED use. Third, most treatments were very short, reducing the likelihood that time passage alone could account for the gains. Fourth, sensitivity analyses retained statistical significance in every case. Finally, treatment adherence and length of treatment were both associated, albeit not significantly, with reduction of ED use.

The implementation of this service required multiple steps, including education, case review, liaison efforts, the information pamphlet and study collaboration. Despite the brevity and competing distractions of the ED encounter, these efforts have allowed the service to grow over the subsequent 2 years to approximately 50 referrals per year. This small portion of possible candidates suggests more can be done to augment referrals. An on-site ISTDP diagnostic clinician would likely increase referrals, as was seen when a resident was present.

Overall, referrals were deemed appropriate, despite the occasional new medical problem identified. Our information pamphlet tells patients that assessment will help determine whether or not emotional factors are causing their problems, clarifying that evaluators don't start with assumptions about causation. This makes referral to this service more acceptable to both EPs and patients.

Future research on the effectiveness of this model is needed, including a randomized controlled trial and external validation. Future research should also examine which patients benefit and whether treatment length is a contributor to ED use reduction. Formal cost-effectiveness research should attempt to replicate previous studies using longer treatment courses..$^{17,18}$ Our findings with a mixed group of moderately trained therapists and students suggest that other centres could also implement this method.

\section{CONCLUSION}

ISTDP diagnostic and treatment services appear to reduce both symptoms and repeat ED visits in those 
with somatization-related MUS. Providing EDs timely access to this type of service could assist with the challenges of repeat ED use.

Acknowledgements: This research was supported by the Dalhousie University Department of Psychiatry, Capital Health and the Nova Scotia Department of Health.

Competing interests: None declared.

\section{REFERENCES}

1. Stephenson DT, Price JR. Medically unexplained physical symptoms in emergency medicine. Emerg Med 7 2006;23: 595-600.

2. Pollard CA, Lewis LM. Managing panic attacks in emergency patients. 7 Emerg Med 1989;7:547-52.

3. Lee J, Dade LA. The buck stops where? What is the role of the emergency physician in managing panic disorder in chest pain patients? CJEM 2003;5:237-8.

4. Fleet RP, Dupuis G, Marchand A, et al. Panic disorder in emergency department chest pain patients: prevalence, comorbidity, suicidal ideation, and physician recognition. Am J Med 1996;101:371-80.

5. Diagnostic and statistical manual of mental disorders: text revision (4th ed). Washington (DC): American Psychiatric Association; 2000.

6. Davanloo H. Intensive short-term dynamic psychotherapy. In: Sadock BJ, Sadock VA, editors. Kaplan \& Sadock's comprebensive textbook of psychiatry. Philadelphia (PA): Lippincott Williams \& Wilkins; 2005. p. 2628-52.

7. Abbass A. Somatization: diagnosing it sooner through emotionfocused interviewing. J Fam Pract 2005;54:231-9.

8. Abbass AA, Hancock JT, Henderson J, et al. Short-term psychodynamic psychotherapies for common mental disorders. Cocbrane Database Syst Rev 2006; (4):CD004687.

9. Abbass AA, Kisely S, Kroenke K. Short-term psychodynamic psychotherapies for somatic symptom disorders. Systematic review and metaanalysis. Psychother Psychosom 2009;78:265-74.

10. Milrod B, Leon AC, Busch F, et al. A randomized controlled clinical trial of psychoanalytic psychotherapy for panic disorder. Am 7 Psychiatry 2007;164:265-72.

11. Wiborg I, Dahl A. Does brief dynamic psychotherapy reduce the relapse rate of panic disorder? Arch Gen Psychiatry $1996 ; 53: 689-94$

12. Fleet RP, Lavoie KL, Martel JP, et al. Two-year follow-up of emergency department patients with chest pain: Was it panic disorder? CJEM 2003;5:247-54.

13. Hinson VK, Weinstein S, Bernard B, et al. Single-blind clinical trial of psychotherapy for treatment of psychogenic movement disorders. Parkinsonism Relat Disord 2006;12:177-80.

14. Baldoni F, Baldaro B, Trombini G. Psychotherapeutic perspectives in urethral syndrome. Stress Med 1995;11:79-84.

15. Hawkins J. The role of emotional repression in chronic back pain: a study of chronic back pain patients undergoing group psychodynamic psychotherapy as treatment for their pain [dissertation]. New York (NY): New York University; 2003.

16. Abbass A, Lovas D, Purdy A. Direct diagnosis and management of emotional factors in chronic headache patients. Cephalalgia 2008;28:1305-14.

17. Abbass A. Intensive short-term dynamic psychotherapy in a private psychiatric office: clinical and cost effectiveness. $A m$ J Psychother 2002;56:225-32.

18. Abbass A. The cost-effectiveness of short-term dynamic psychotherapy. Expert Rev Pharmacoeconomics Outcomes Res 2003;3:535-9.

19. Derogatis LR, Melisaratos N. The brief symptom inventory: an introductory report. Psychol Med 1983;13:595-605.

20. Abbass AA, Joffres MR, Ogrodniczuk JS. A naturalistic study of intensive short-term dynamic psychotherapy trial therapy. Brief Treatment Crisis Interven 2008:164-170.

21. Abbass AA. Office-based research in intensive short-term dynamic psychotherapy (ISTDP): data from the first 6 years of practice. AD HOC Bull Short-term Dynamic Psychother 2002;6:5-13.

22. Abbass A, Sheldon A, Gyra J, et al. Intensive short-term dynamic psychotherapy for DSM-IV personality disorder: a randomized controlled trial. 7 Nerv Ment Dis 2008;196:211-6.

23. Derogatis L. Brief Symptom Inventory: administration, scoring and procedure manual. Minneapolis (MN): National Computer Systems; 1993.

Correspondence to: Dr. Allan Abbass, 5909 Veterans Memorial Lane, Rm. 8203, Abbie J. Lane Building, QEII Health Sciences Centre, Halifax NS B3H 2E2; allan.abbass@dal.ca 